\title{
Conhecer para proteger: culturas e salvaguarda do patrimônio arquitetônico em duas capitais lusófonas
}

\section{Knowing to protect: cultures and preservation of the architectural heritage in two lusophone cities}

\author{
Rodrigo Cit Ramos Lopes ${ }^{1}$, Letícia Dias Fantinel ${ }^{2}$
}

\begin{abstract}
Resumo
O artigo se propõe a identificar e analisar questões envolvidas na salvaguarda do patrimônio arquitetônico nas cidades de Salvador e Lisboa, através das influências das dimensões arquitetônica e legislativa. Para isso, fizemos uso de revisão bibliográfica e documental que, examinadas através de análise de conteúdo, evidenciou semelhanças e diferenças nos contextos estudados. Os resultados apontam para similaridades entre arquiteturas e legislações de proteção, com divergências pouco significativas. No entanto, percebemos discrepância entre os instrumentos de proteção e os recursos humanos e materiais empreendidos na salvaguarda dos bens protegidos. Tais características, somadas a outros elementos, evidenciam uma maior preocupação lisboeta com o patrimônio se comparado a Salvador, indicando diferentes relações da população com seus espaços urbanos e sua história. Abre-se, assim, um campo de discussões sobre patrimônio, necessariamente interdisciplinar, já que os aspectos envolvidos passam pela questão legal, mas também pela história e contexto cultural do patrimônio e da própria cidade.
\end{abstract}

Palavras-chave: Patrimônio. Arquitetura. História. Salvador. Lisboa.

\begin{abstract}
This article aims to identify and analyze issues about the preservation of the architectural heritage in the cities of Salvador and Lisbon, through the influences of architectural and legislative dimensions. For this, we used the literature review and documentary research using content analysis. The results revealed similarities and differences within both cities. The conclusions show similarities between architectures and protection law in both countries, with few significant differences. However, we noticed a discrepancy between the protection instruments and also human and material resources, undertaken to safeguard the protected places. These characteristics, combined with other elements, show a greater concern about heritage in Lisbon, if compared to Salvador, indicating different relationships of people with their urban spaces and, ultimately, with their history. It opens a field of discussions about heritage, which is interdisciplinary, since the background involved is legal, but also historical and cultural.
\end{abstract}

Keywords: Heritage. Architecture.History. Salvador. Lisbon.

\footnotetext{
${ }_{1}^{1}$ Perito Criminal Federal no Departamento de Polícia Federal. E-mail: rodrigocit@gmail.com

2 Universidade Federal do Espírito Santo (UFES). E-mail: leticiafantinel@gmail.com

Cad. de Pesq. Interdisc. em Ci-s. Hum-s. Florianópolis, Santa Catarina, Brasil, ISSN 1984-8951 v.14, n.105, p.139-164 ago/dez 2013
} 


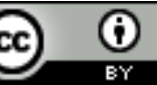

Esta obra foi licenciada com uma Licença Creative Commons - Atribuição 3.0 Não Adaptada.

\title{
Introdução
}

\begin{abstract}
Porto, ladeiras, construções dos séculos passados e o mar. Cidades de dois andares, com elevador, escadarias e pessoas dispostas a conversar sobre tantas coisas nas ruas. Lisboa e Salvador têm muito em comum, e de incomum, em relação ao resto do mundo. As culturas que se misturaram nas duas cidades continuam a se corresponder. É muito fácil encontrar Salvador em Lisboa e Lisboa em Salvador (WEINSTEIN, 2007, p. 1).
\end{abstract}

Salvador e Lisboa são cidades muito semelhantes, como argumenta Weinstein (2007), não somente física e geográfica, mas, também, histórica e cultural. Um observador qualquer pode, em uma rápida visita à capital portuguesa, enxergar muito dos soteropolitanos nos lisboetas (ou seria o contrário?), em situações simples de diálogo ou observação do comportamento em espaços públicos. Nas ruas, por exemplo, presenciamos uma conduta de receptividade e esforço no auxílio a turistas estrangeiros, mesmo sem o domínio da língua inglesa, observamos certa "desordem urbana organizada", perdida e encontrada em ladeiras e ruas estreitas, em meio a construções barrocas e em estilo colonial. Não obstante, muito facilmente, notamos a influência lusa na arquitetura da capital baiana.

Merecem igual destaque outras semelhanças notáveis entre Salvador e Lisboa, desta vez de cunho natural, como o relevo acidentado (ambas são reconhecidas por suas ladeiras íngremes) e o abraço marítimo (com a Baía de Todos os Santos e a Baía de Lisboa). Salientamos também o componente religioso que marca as cidades, na medida em que ambas foram e são influenciadas fortemente pelo catolicismo, o que vemos através da presença maciça de igrejas e catedrais. Lisboa e Salvador, cidades historicamente múltiplas, caracterizam-se como locais em que a influência da diversidade continua a traçar marcas indeléveis no cotidiano citadino. Hoje, metrópoles dentro de seus contextos, convivem com problemas e desafios urbanos comuns: inchaço da população, pobreza, marginalização, entre outros. São cidades vinculadas por laços históricos, culturais, religiosos, turísticos, etc. 
No que tange especificamente à conservação e restauro do patrimônio arquitetônico, mote do presente artigo, podemos dizer que, apesar das semelhanças de tipologia na arquitetura, as cidades apresentam diferentes mecanismos de proteção, estes evidenciados por suas respectivas legislações. Merece destaque inicial a diferença entre as terminologias, sendo utilizado o tombamento, no caso brasileiro, e a classificação, em terras portuguesas. No entanto, é possível afirmar que, apesar do uso de diferentes nomenclaturas, os usos são muito similares na prática, como será apresentado oportunamente.

Também cumpre salientar a quantidade de bens tombados ou classificados em Lisboa e Salvador, com vistas a melhor entender o sistema de salvaguarda em cada local. $\mathrm{Na}$ capital portuguesa, constam, atualmente, 236 bens classificados, enquanto na cidade brasileira em questão, somam-se 148 bens tombados nas esferas federais e estaduais. Tal diferença torna-se ainda mais significativa ao verificarmos que Lisboa ocupa uma área de aproximadamente $12 \%$ do espaço de Salvador e possui uma população cerca de cinco vezes menor. Obviamente, esses dados precisam ser considerados dentro do contexto social e histórico em que estão inseridos, todavia, são indicadores de mecanismos envolvidos na salvaguarda do patrimônio arquitetônico em cada localidade.

Nesse sentido, o presente artigo tem como objetivo geral identificar e analisar as questões envolvidas na salvaguarda do patrimônio arquitetônico nas cidades de Salvador e Lisboa, através das influências da dimensão arquitetônica e em termos de seus instrumentos de proteção. Para isso, a metodologia seguida foi a da revisão bibliográfica e documental que, tendo seus dados examinados através da técnica de análise de conteúdo, evidenciou paralelos e entrecruzamentos no âmbito dos dois contextos estudados.

O presente artigo está estruturado em cinco itens, excluindo-se esta introdução. A seção seguinte apresenta questões teóricas que norteiam o texto. Depois dela, o roteiro metodológico utilizado durante a pesquisa. A seguir, elucidamos os contextos espaciais estudados, trazendo uma breve história das cidades de Lisboa e Salvador. Em seguida, serão discutidos os instrumentos de proteção e salvaguarda do patrimônio cultural português e brasileiro, com vistas à análise comparativa, com foco tanto na arquitetura como nos normativos e legislações vigentes em cada cidade. Por fim, à guisa de conclusão, expõem-se 
críticas e sugestões sobre o tema, tendo como foco possíveis caminhos para o salvaguardado patrimônio cultural e pontos de partida para estudos posteriores.

\section{Patrimônio, cultura, história e cidade: breves questões teóricas}

É possível dizer que diferentes processos sociais vêm mudando, com o tempo, as relações nas sociedades ocidentais contemporâneas. Como resultado de tais processos, vemos, entre outros fenômenos, a emergência de uma "consciência patrimonial" em diversas cidades pelo mundo (ANICO, 2005). Na visão de Anico (2005), frente a uma ameaça - real ou imaginada - de ruptura e desaparecimento de referentes culturais pela assimilação por uma cultura transnacional, assistimos a uma crescente valorização de identidades locais, que, acompanhada por um sentimento nostálgico em relação ao passado, produz diferentes formas de patrimonialização de referentes culturais. Como consequência de um declínio das histórias nacionais e proliferação de narrativas alternativas e diversas, tem-se a criação de inúmeros museus e sítios patrimoniais (ANICO, 2005).

Em uma concepção semelhante, Zamin (2006) afirma que a preocupação com a salvaguarda de bens culturais acentua-se a partir da experiência transformadora da modernidade, contexto em que as práticas de preservação são construções que estão estritamente vinculadas a valores, a visões de mundo, e consequentemente, a culturas. Com isso, abrem-se discussões para que a própria noção de patrimônio seja reformulada, e constantemente colocada em mutação (GRAMMONT, 2006).

Nesse sentido, o Patrimônio Arquitetônico ao qual nos referimos neste artigo, tem como elementos básicos, além de sua dimensão material, um forte componente identitário e, até mesmo, afetivo (FERREIRA, 2004). A retórica do patrimônio sustenta a importância de sua salvaguarda na medida em que está relacionado à memória, identidade e cultura dos povos (URIARTE, 2010). Assim, aproxima-se do conceito de "lugares de memória" de Nora (1997), locais que fixam um estado de coisas, congelando tempo e espaço, museificando algo que não mais existe. Não obstante, esse sentido de patrimônio é, de fato, investido em virtude da experiência, da atribuição de significado ao espaço físico, social e simbólico. É o significado do espaço que o transforma em patrimônio (FERREIRA, 2004). 
Pensar pura e simplesmente em "cidade" implica visualizar espaços compostos de ruas, praças e casas, por outro lado, pensar na cidade em que se vive ou em que se viveu, especificamente, consiste em imaginar as praças nas quais se passou a infância, as ruas pelas quais se andou, os locais que materializam a história e a identidade individual e coletiva. No primeiro exemplo, a cidade é uma realidade no espaço; no segundo caso, a cidade é uma realidade no tempo (MACEDO, 1993). E é na interseção entre espaço e tempo que se criam, reproduzem e circulam os diferentes significados do espaço da cidade, entre eles o de patrimônio (PESAVENTO, 2007).

Lisboa e Salvador são cidades com muitos espaços investidos da categoria de patrimônio, por vezes concentrados em um centro histórico, mas também espalhados pelo território. São realidades no espaço e no tempo que se materializam enquanto fixadores de histórias, identidades, culturas. Nesse sentido, o próximo item abordará alguns dos elementos materializados pelos patrimônios nas duas cidades.

\section{Patrimônios em Lisboa e Salvador}

Conforme já destacado, Lisboa e Salvador possuem particularidades que podem chamar a atenção do observador por conta de suas semelhanças. A mesma História que construiu a diversidade entre as cidades é a que costura homogeneidades que ligam as metrópoles. Relacionadas desde a época do descobrimento, conectadas no período colonial e detentoras de similaridades materiais e imateriais, seja no campo da arquitetura, do patrimônio, da cultura, dentre outros, Lisboa e Salvador se prestam a uma análise ampla e contextual cujos elementos e dimensões mostram-se, muitas vezes, complementares.

A cidade de Lisboa pode ser caracterizada, desde seu princípio, por uma dupla condicionante histórica e cultural, já que se constituiu como uma cidade atlântica, ainda que de matriz mediterrânea. Esta dupla condição da cidade, veiculada por uma "dominação" atlântica, mas, também, por uma "resistência" mediterrânea, teve tais influências plasmadas por um componente religioso (matrizes islâmica, cristã e, mais tarde, judaica). Como consequência, a cidade detém, contemporaneamente, um quadro social heterogêneo, agregando múltiplos e 
variados comportamentos, modos e estilos de vida, bem como referências culturais (FERREIRA, 2002).

Apesar da vida dos portugueses ter sido predominantemente rural por séculos, as cidades foram muito importantes, com destaque para a capital nacional. Marcada pela ocupação romana (entre os séculos II a.C. e V d.C.), quando a cidade era chamada de Olisipio, e posteriormente pela ocupação de povos ditos "bárbaros" (a partir do ano de 711), Lisboa também passou por um período de domínio árabe. Este domínio a transformou em uma das mais importantes cidades da lbéria muçulmana, quando recebeu o nome de Al-Uxbûna. Em 1147, foi ocupada pelos cristãos através da conquista de D. Afonso Henriques, primeiro rei de Portugal, e tornou-se capital do reino em 1255 (SCOTT, 2010).

A localização privilegiada facilitou o acesso ao oceano, culminado com as longínquas expedições portuguesas além-mar, que, através do comércio, transformaram Lisboa no maior empório do mundo ocidental (SCOTT, 2010). O fervilhar de nativos e estrangeiros, propiciado pelas navegações, contribuiu para gerar uma Lisboa habituada à multiplicidade. Já no século XVI, Lisboa é descrita como uma "cidade de mui e desvairadas gentes" segundo relato de Luís de Camões, alusão à diversidade de sentidos e significados circulando em seu espaço aberto a "espantos" e "desvarios" (FERREIRA, 2002). Nesse contexto, a capital portuguesa passa por um crescimento significativo nos séculos $\mathrm{XV}, \mathrm{XVI}$ e mesmo XVII. Ainda que menor que Paris, Londres ou Nápoles, era uma cidade enorme para o tamanho do reino, podendo ser comparada, à época, à Veneza ou à Amsterdã (RODRIGUES, 1994). Assim, considerada por alguns a "cabeça macrocéfala do reino" (RODRIGUES, 1994, p. 95), Lisboa veio sobrepujando-se, ao longo dos séculos, a outros centros urbanos de Portugal, crescendo de forma significativa e centralizando a vida do país, o que é verdade até os dias atuais (BAPTISTA, 1994).

Voltando ao século XIX, é possível dizer que o urbanismo típico desse período, resposta aos problemas criados pelo crescimento urbano europeu, também atingiu Lisboa. Acreditava-se que a resolução do problema da salubridade e a renovação urbanística passavam pela adoção de equipamentos modernos semelhantes aos que existiam em outras cidades da Europa (SILVA; MATOS, 2000). Ruas mais amplas, consideradas essenciais para a salubridade urbana, bem como a 
criação de infraestruturas de transportes e drenagem e de abastecimento de água, foram projetos executados à época (SILVA; MATOS, 2000).

Já no século XX, Lisboa e sua área metropolitana, tal como conhecemos hoje, iniciaram sua estruturação nas décadas de 50 a 70 . Tal processo tem por características, além de uma forte centralização na capital, que polariza a maioria dos empregos em serviços e indústria, o consequente crescimento de assimetrias entre o centro metropolitano e periferias. Já na década de 1980, ocorrem melhorias no nível de vida e mudança nos hábitos de consumo (principalmente com a inauguração de grandes centros comerciais, as chamadas grandes superfícies). Acompanhada da expansão da cidade, tem-se também o aumento da coroa urbana e consequente suburbanização da cidade e deslocamento do centro tradicional (BARATA SALGUEIRO, 1997).

Contemporaneamente, a integração europeia faz com que Portugal passe a ser visto como uma porta de entrada para a Europa, o que tem atraído muitos migrantes (BARATA SALGUEIRO, 1997). Contudo, apenas nos anos 1990, o país começa a se assumir como de imigração, afirmando-se como Capital Atlântica da Europa e desenvolvendo políticas locais que começam a refletir a diversidade cultural (SANTOS, 2008).

Assim sendo, cidade historicamente cosmopolita e multicultural, Lisboa apresenta como grande desafio, na atualidade, o desequilíbrio sócio-urbanístico decorrente de situações de exclusão e marginalização de parte do contingente populacional, especialmente imigrante (SANTOS, 2008). Hoje, sua população é de 547 mil habitantes, enquanto que a área metropolitana, a Grande Lisboa, possui cerca de 2 milhões de residentes, número significativo frente aos 10,5 milhões presentes no país (INSTITUTO NACIONAL DE ESTATÍSTICA, 2011).

Do outro lado do Atlântico, Salvador, a antiga Cidade da Bahia, nasceu como uma fortificação, com o objetivo de centralizar a organização administrativa e assegurar defesa e posse da nova colônia portuguesa (DOREA, 2006). A cidade, construída sob influência lusa medieval, teve, desde sua fundação, um espaço urbano cuja fisionomia evidenciava tal aspecto, visível nas ruas tortuosas e ladeiras íngremes (RISÉRIO, 2004). Fundada no início do período colonial, para que detivesse funções político-administrativas e mercantis, Salvador sediou o governo geral do Brasil até 1763 , configurando-se como a mais importante cidade brasileira 
nesse período. Todavia, com a transferência da capital para o Rio de Janeiro, o declínio da base agroexportadora local e, mais recentemente, a constituição de um mercado nacionalmente unificado e a concentração industrial no eixo Centro-Sul, a cidade passou a vivenciar um longo período de estagnação econômica e populacional (MARIANO, 2009). A ampliação de sua área urbanizada ocorreu de forma lenta até meados do século $X X$, quando a cidade começou a ser atingida por transformações significativas (CARVALHO; PEREIRA, 2007).

O atraso da urbanização no interior não impediu, contudo, o avanço da metropolização de Salvador. A descoberta de petróleo em solo baiano e o desenvolvimento da economia agrícola, especialmente em decorrência do cultivo de cacau no sul do Estado, foram fatores atribuídos por Rubim, Coutinho e Ancintara (1990) como principais responsáveis pelas modificações desencadeadas na cidade.

A Bahia torna-se o primeiro estado brasileiro a produzir petróleo, e, durante praticamente três décadas, será o único produtor nacional, aumentando significativamente o volume de investimentos e salários em âmbito local. Assim, ampliam-se as camadas de renda média e alta e a população, de forma geral, tem um crescimento acentuado em função do estabelecimento de migrantes, esses fatores resultam, por sua vez, em uma alta demanda imobiliária. Tal fenômeno acaba por "empurrar" uma parcela da população, seus setores mais pobres, para áreas então periféricas da cidade, enquanto as regiões com melhor infraestrutura urbana passaram a ser ocupadas pelas camadas privilegiadas (RUBIM; COUTINHO; ANCINTARA, 1990).

A modernização e expansão de Salvador, processo que ocorreu de forma abrupta entre as décadas de 1960 e 1970, foi responsável pela realização de grandes obras que definiram muitos dos caminhos da expansão urbana, além de participar na intensa ocupação informal de famílias de baixa renda na periferia (CARVALHO; PEREIRA, 2007). Assim, na década de 1980, consolidou-se um novo centro urbano, impulsionado por grandes empreendimentos públicos e privados (SERPA, 2007). Essa nova centralidade direcionou a expansão urbana no sentido da orla norte e contribuiu para o gradativo esvaziamento do centro tradicional na área antiga da cidade (CARVALHO; PEREIRA, 2007).

Assim como ocorrido em outras metrópoles, a exemplo da própria Lisboa, o centro tradicional de Salvador foi perdendo a característica de centralidade para 
outras áreas, em regiões mais afastadas. Como consequência desse deslocamento das antigas áreas centrais para as bordas e para o periurbano, temos o empobrecimento desses espaços, seu decréscimo demográfico, além de uma sucessiva constituição de novas centralidades, associadas à multiplicação de artefatos de impacto no espaço metropolitano (complexos empresariais e de convenções, grandes centros de comércio e serviços, hipermercados, parques temáticos, etc.), acentuando uma metropolização estendida que prolonga a cidade para várias direções (CARVALHO; PEREIRA, 2007, ARANTES; CARVALHO, 2009).

Ao sofrer tais impactos, provocados pelo processo de reestruturação urbana, Salvador teve, pois, sua dinâmica alterada, tornando-se uma cidade poli(multi)nucleada, característica que faz com que suas centralidades se dispersem por algumas áreas de seu território (SANTOS, 2008).

Hoje, Salvador é a terceira cidade mais populosa do Brasil (a primeira é São Paulo e a segunda, Rio de Janeiro), com mais de 2,5 milhões de habitantes (IBGE, 2010). Uma cidade plural, com identidade cultural multifacetada, síntese da dinâmica cultural da Bahia - contemporânea, cosmopolita, barroca, tradicional (FISCHER, 1997).

Como vimos, a História liga as duas cidades. Salvador teve sua criação determinada por uma forte influência lisboeta, arquitetônica e cultural. E cultivamos, até hoje, muitas semelhanças, no idioma, nos hábitos e costumes, na gênese diversa e agregadora (e por vezes desagregadora) das multiplicidades. Além disso, Lisboa e Salvador são cidades que vêm sendo contemporaneamente afetadas por fenômenos similares, igualmente característicos de diversas metrópoles atuais, como o enfrentamento de um crescimento urbano desenfreado e abrupto, além da criação de bolsões de pobreza em decorrência da inaptidão em tratar de questões relativas a desigualdades econômicas e sociais. Essas similaridades também se apresentam no domínio da gestão do patrimônio arquitetônico das cidades, razão pela qual a presente análise pode trazer dados interessantes nesse campo. Sendo assim, de modo a esclarecer os percursos metodológicos da presente pesquisa, expomos brevemente os procedimentos utilizados neste artigo.

\section{Método}


A presente pesquisa é caracterizada como exploratório-descritiva. No que concerne ao seu caráter exploratório, é possível dizer que ela auxilia no processo de aquisição de maior familiaridade com o problema, com vistas a torná-lo mais explícito (GIL, 2002). Já com relação à dimensão descritiva da pesquisa, esta corresponde à busca de compreensão do fenômeno (GIL, 2002).

Assim, para desenvolver este estudo, partimos da pesquisa bibliográfica na fase exploratória. Nas etapas subsequentes, foram utilizadas informações de diferentes naturezas, compostas por dados referentes às legislações dos dois países, aos imóveis tombados nas cidades analisadas, além de dados observacionais coletados pelos pesquisadores in loco.

Foram analisados os imóveis tombados em Salvador, tanto na esfera estadual quanto federal, na busca por convergências que caracterizassem a arquitetura local salvaguardada. Posteriormente, a partir dos elementos destacados na análise anterior foi realizada uma busca em edificações lisboetas na procura por possíveis vinculações arquitetônicas, que melhor caracterizassem a influência portuguesa. Por fim, a título de ilustração, apresentamos algumas edificações que melhor sintetizam os padrões encontrados concomitantemente em Salvador e Lisboa. Nesse ínterim, optamos por não analisar as características comuns da arquitetura militar em Salvador e Lisboa, em virtude da construção direta pela coroa portuguesa, principalmente nos séculos XVII e XVIII, e pela pouca intervenção até o tombamento (IPAC-BA, s/d), com exceção para as ações de preservação dos imóveis.

Dessa forma, com base nos dados aqui citados, foi realizada uma análise comparativa, na medida em que esta pode auxiliar no sentido de tornar-nos sensíveis "ao número e aos tipos de propriedades que podem pertencer a fenômenos que, de outra forma, não seriam observados ou só seriam observados bem mais tarde" (STRAUSS; CORBIN, 2008, p. 87).

Nesse sentido, com o objetivo de sustentar as análises aqui realizadas, apresentamos, a seguir, os principais eixos norteadores desse texto do ponto de vista teórico.

\section{Lisboa e Salvador: patrimônios e instrumentos de proteção}




\subsection{Patrimônios arquitetônicos}

A arquitetura, elemento claramente visível dentre os selecionados em nossa análise, pode ser destacada como aspecto essencial na comparação entre as cidades de Salvador e Lisboa. No caso da capital portuguesa, como já abordado neste artigo, a arquitetura de suas edificações, especialmente as classificadas, foi amplamente marcada pela influência de diversos povos que se relacionaram com sua população e território. Todavia, cabe ressaltar que o período de dominação romana não chega a imprimir suas características tão fortemente nas concepções arquitetônicas como em outras cidades europeias, em decorrência da distância geográfica em relação ao centro do império e das ocupações posteriores sofridas por Lisboa.

Por outro lado, é possível afirmar que o período de intensa ocupação muçulmana influenciou, de forma mais marcante, a arquitetura lisboeta, o que pode ser facilmente notado, por exemplo, na concepção de desenvolvimento das edificações através de um pátio central e, obviamente, na larga utilização de azulejos nas fachadas (Cf. Figuras 1 a 4). O término da dominação muçulmana, marcado pela conquista cristã através das Cruzadas, resulta, até os dias atuais, em uma população católica em sua esmagadora maioria, e influencia fortemente a arquitetura protegida como patrimônio cultural (vasta presença de igrejas e catedrais).

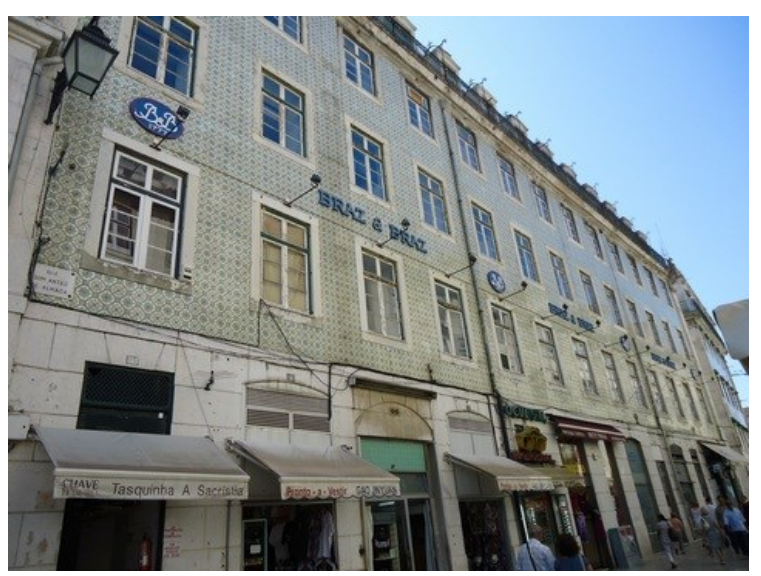

Figura 1: Fachada em azulejos - Lisboa

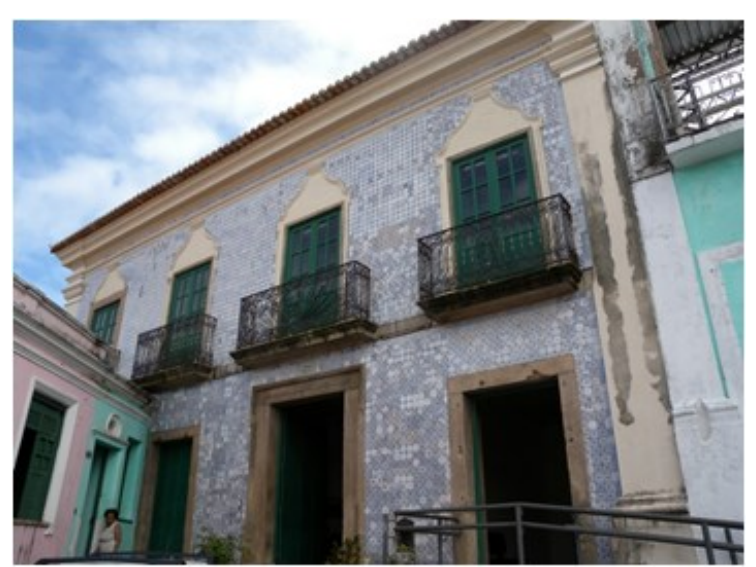

Figura 2: Fachada em azulejos - Salvador 


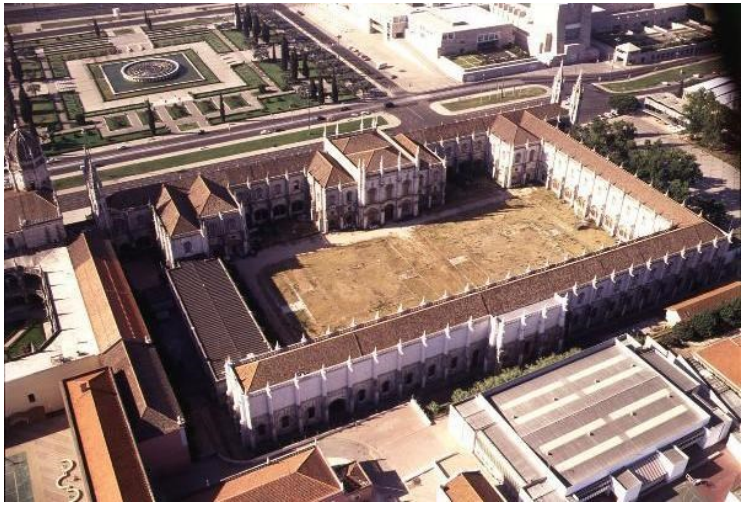

Figura 3: Mosteiro dos Jerónimos - Lisboa Fonte: IGESPAR (2012).

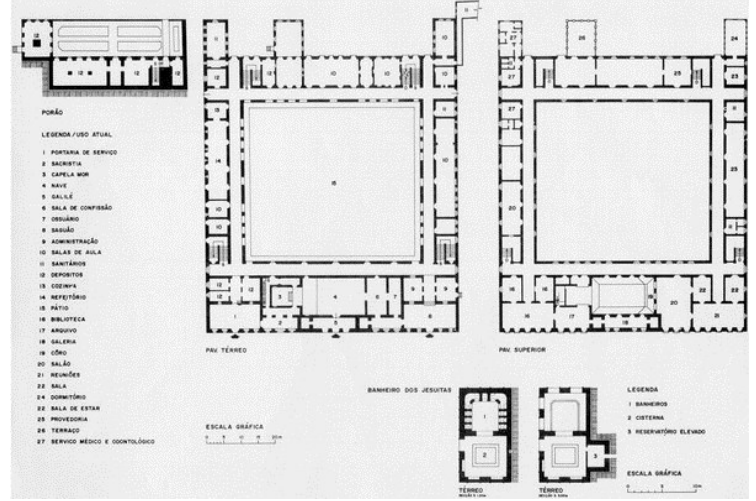

Figura 4: Casa Pia - Salvador Fonte: IPAC-BA (s/d).

Tão importante quanto às informações supracitadas na influência da atual arquitetura lisboeta foi o célebre terremoto ocorrido em Portugal, no ano de 1755, que atingiu nove graus na escala Richter, tendo sido seguido por um tsunami e um incêndio, fenômenos que praticamente destruíram a capital. Conforme destaca Fonseca (2005), a análise do desastre provocou profundas reflexões por intelectuais da época, principalmente por iluministas, visto que Portugal era um dos países mais religiosos da Europa - e muitos habitantes interpretavam acontecimentos do tipo: castigo divino.

Como medidas para mitigação dos danos e reconstrução de Lisboa, o Secretário de Estado Sebastião José de Carvalho e Melo, futuro Marquês de Pombal, assumiu o controle da situação com apoio do rei D. José I. Sendo assim, além das providências imediatas, como distribuição de mantimentos, desobstrução das vias e remoção dos mortos, iniciaram-se os estudos para a reconstrução de Lisboa. Foram apresentadas as seguintes opções para a reconstrução: (1) manutenção do local antigo, com suas características; (2) redesenho das ruas, de forma que elas fossem alargadas; (3) nivelamento de toda cidade, usando entulho para aplainar alguns pontos e limitando a altura das edificações à largura da rua; e, finalmente, (4) edificação de um novo núcleo urbano em outro local. À época, optouse pela terceira alternativa: Lisboa foi nivelada e teve a altura dos novos prédios construídos limitada (FONSECA, 2005). A propósito, é interessante notar que o desastre encontra-se, até os dias atuais, muito marcado na cidade de Lisboa, seja na arquitetura local, seja na memória coletiva, o que é visível através das ruínas, das edificações e ruas reconstruídas, ou mesmo dos monumentos erigidos com o intuito de rememorar a catástrofe e a reconstrução passadas. 
Já no além-mar, em terras brasileiras, a análise dos imóveis soteropolitanos reconhecidos como patrimônio cultural passa, obrigatoriamente, pelas técnicas construtivas e padrões arquitetônicos portugueses do período colonial. Ademais, também é preciso atentar à possibilidade de um caminho inverso da influência arquitetônica entre Lisboa e Salvador: a capital soteropolitana, por guardar muitas semelhanças do ponto de vista arquitetônico de suas edificações com a capital portuguesa, serviu como modelo a Lisboa no momento da reconstrução da cidade depois do referido terremoto (WEINSTEIN, 2007).

Como exemplo na arquitetura civil convergente, é possível apontar o imóvel conhecido como Quinta do Tanque ou dos Padres (Casa Suburbana de São Cristovão), possuindo partido em "U", de origem renascentista, do século XVIII. Esta concepção também foi adotada na casa da Torre de Garcia D'Ávila (séculos XVI / XVII), no município de Mata de São João, na Bahia, e no Palácio dos Condes de Galveias, edifício do século XVII localizado em Lisboa (cf. Figuras 5 e 6).

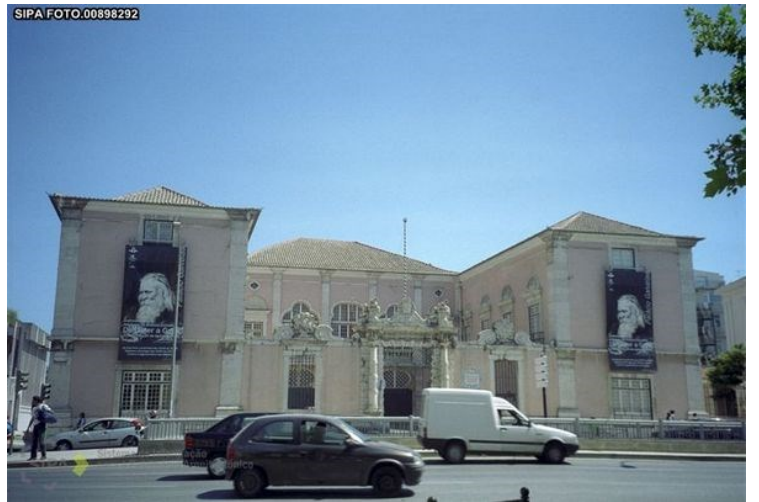

Figura 5: Palácio Galveias - Lisboa Fonte: SIPA (2012).
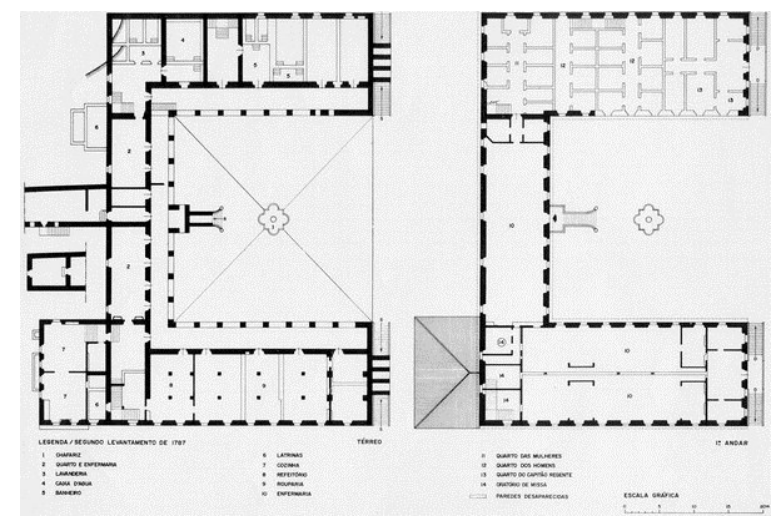

Figura 6: Quinta do Tanque - Salvador Fonte: IPAC-BA (s/d).

Igualmente, cumpre destacar a Casa das Sete Mortes, localizada no centro histórico de Salvador, considerada um dos "melhores exemplares" de casa urbana desenvolvida em torno de um pátio interno (IPAC-BA, s/d), apresentando galerias ao redor do pátio no pavimento térreo e superior. Esta concepção, adotada no Brasil no final do século XVII, conforme exposto anteriormente, nunca foi abandonada na Península Ibérica, devido à sobrevivência da tradição romana e muçulmana (cf. Figuras 7 e 8 ). 


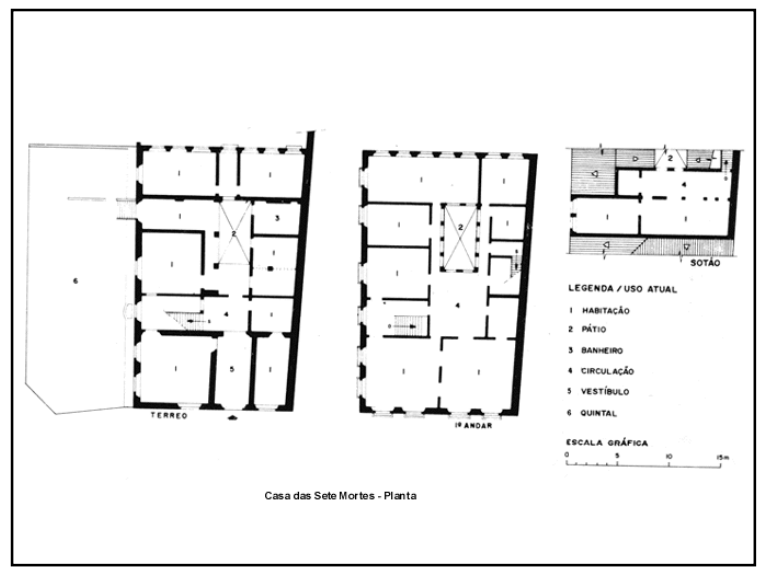

Figura 7: Planta original do imóvel Fonte: IPAC-BA (s/d).

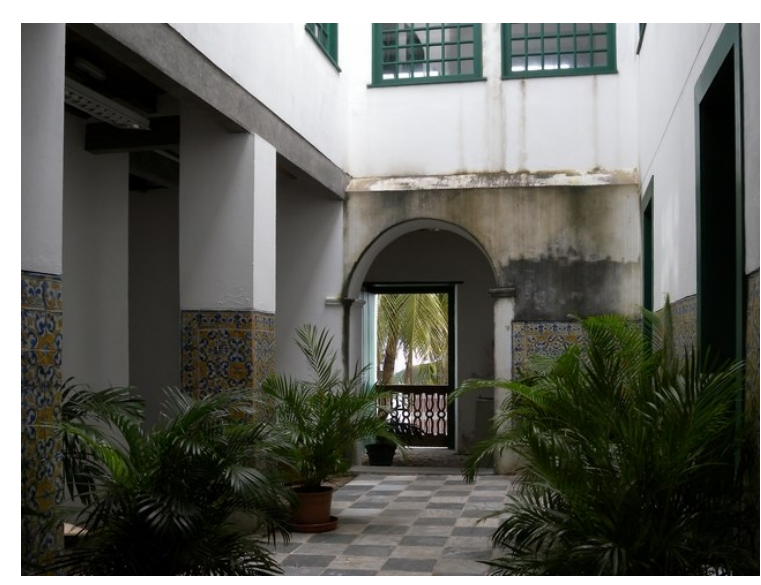

Figura 8: Pátio Central

No que tange à arquitetura religiosa, é exemplo direto da influência lusitana a emblemática fundação do mosteiro beneditino em Salvador - hoje, Mosteiro de São Bento da Bahia, trazendo os monges ao Brasil, em 1583 (HERNANDEZ, 2010). Destaca a autora que este primeiro estabelecimento seguiu as regras de São Bento, tanto em relação à arquitetura quanto em relação às condições de localização das casas religiosas, de modo a disporem de suprimentos e equipamentos necessários, como água, moinho, horta e oficinas.

Não eram determinadas apenas as regras de construção e localização dos mosteiros brasileiros em relação aos portugueses, também eram adotadas as mesmas estruturas administrativas e funcionais. Sendo assim, as casas religiosas recebiam as orientações da Congregação, inclusive no que tange à circulação dos monges entre as unidades, unificando técnicas nos diferentes ramos da construção relacionados à recuperação de bens móveis e imóveis.

No Brasil, em período mais recente, conforme salienta Pinheiro (2006), a questão da identidade nacional no Estado Novo somou-se à busca pela autonomia da arte nacional (de viés modernista), privilegiando a adaptação dos modelos formais europeus às condições locais, o que resultou em uma nova arquitetura, caracterizada como brasileira. Para tanto, a arquitetura colonial servia de exemplo para esta leitura, enfatizando-se o processo de adequação entre a arquitetura de matriz da Europa e o clima, os materiais disponíveis, os programas, etc.

Enfim, a presente seção buscou apresentar, de forma exemplificativa, algumas convergências entre a arquitetura soteropolitana e a lisboeta, e um pouco da história que ajudou a formar estas cidades, na busca pela caracterização das 
influências construtivas entre as capitais. Tendo abordado alguns dos emblemáticos exemplos que ilustram essa convergência, apresentamos os instrumentos que os protegem, em ambos os países.

\subsection{Instrumentos de proteção}

Primeiramente, para fins desta análise, destacamos os instrumentos legislativos de proteção do patrimônio. Conforme destaca Jorge (2000), alguns dos primeiros registros de salvaguarda do patrimônio português datam de 1721, através do Rei D. João V, ao determinar que "daqui em diante, nenhuma pessoa de qualquer estado, qualidade e condição que seja desfaça ou destrua em todo, nem em parte qualquer edifício que mostre [antiguidade] ainda que em parte esteja arruinado" (JORGE, 2000, p. 6). Em consonância, o autor salienta que, na segunda metade do século XIX, o Rei Fernando II ordenou o restauro das sés de Lisboa e de Coimbra, da abadia de Alcobaça, dos conventos da Batalha, de Tomar e de Mafra e da Torre de Belém. Também cabe destaque o início do processo de inventariação dos monumentos portugueses, em 1880 (JORGE, 2000).

Ao longo dos anos seguintes, foram criadas leis e normativas específicas que nortearam e possibilitaram a atual legislação de salvaguarda do patrimônio histórico. No entanto, somente através da Lei 13/1985, Portugal efetivamente conheceu uma lei específica que formulasse os aspectos jurídicos relativos à salvaguarda do patrimônio cultural, em sentido amplo.

No caso do Brasil, é importante discorrer acerca do contexto político e cultural, no qual foi criado o decreto-lei 25/1937, principal lei de salvaguarda, vigente até os dias atuais. Nesse sentido, a possibilidade de promulgação do referido instrumento legal foi determinada pela Constituição de 1934 ao apresentar, pela primeira vez, o princípio da função social da propriedade. Além disso, destacamos a influência dos intelectuais, na defesa pela preservação dos testemunhos históricos, e o papel do Estado novo na busca por elementos que possibilitassem a consolidação de uma identidade nacional.

A legislação atual portuguesa é determinada principalmente pela Lei 107/2001, que estabelece as bases da política e do regime de proteção e valorização do patrimônio cultural e revogou a Lei 13/1985. Tal instrumento determina a proteção e valorização como tarefa fundamental do Estado, buscando Cad. de Pesq. Interdisc. em Ci-s. Hum-s. Florianópolis, Santa Catarina, Brasil, ISSN 1984-8951 
garantir direito de todos à fruição do patrimônio cultural. Diferentemente da legislação brasileira, já se encontra prevista nos termos da lei, a contratualização da administração do patrimônio cultural, assim como a preservação e valorização do patrimônio cultural situado no território nacional ou fora dele, que tenha testemunhado capítulos da história comum.

A lei portuguesa considera como bens culturais aqueles que "representem testemunho material com valor de civilização ou de cultura" (LEI 107/2001, 2001, p. 5811), e prevê a classificação dos bens móveis e imóveis em: bens de interesse nacional (representam um valor cultural de significado para a nação); bens de interesse público (são de importância nacional, mas que se mostrem desproporcionados à classificação anterior); e bens de interesse municipal (são valor cultural de significado predominante para determinado município, em âmbito local). No Brasil, não há ingerência da união no caso dos bens de interesse regional, sendo necessário apenas um tombamento estadual ou municipal independente e não vinculado à salvaguarda nacional.

No que tange às zonas de proteção, as legislações brasileira e portuguesa aproximam-se: não há distância pré-concebida, sendo determinado caso a caso, de acordo com o possível dano ao imóvel tombado. Entretanto, no caso lusitano, esta determinação surgiu somente em 2009, através do decreto-Lei 309/2009, sendo que, anteriormente, eram adotados 50metros de forma automática. Igualmente em consonância com a lei brasileira, a norma lusa determina que impulso do procedimento de classificação ou inventariação pode provir de qualquer pessoa ou organismo, público ou privado, nacional ou estrangeiro. No entanto, cabe destacar que a possibilidade de instauração do processo de tombamento por qualquer pessoa física ou jurídica no Brasil surgiu apenas na Portaria 11/1986.

Nos últimos anos, Portugal tem produzido outras leis de elevada importância para a salvaguarda do patrimônio, com destaque para o Decreto-lei 96/2007, que criou o IGESPAR (Instituto de Gestão do Património Arquitectónico e Arqueológico). Em âmbito brasileiro, a lacuna causada pela falta de regulamentação do Decreto-lei 25/1937 foi suprida através de portarias do IPHAN (Instituto do Patrimônio Histórico e Artístico Nacional), tanto em âmbito nacional quanto local. Sendo assim, ao longo das décadas seguintes à lei principal, ocorreram definições de gabaritos no entorno de monumentos tombados em diferentes locais. Esta forma de regulamentação traz 
consigo a necessidade de tornar mais públicos e transparentes os critérios de análise do IPHAN, ao passo que o uso das portarias como instrumentos de proteção de tecidos urbanos apresenta-se como mais flexível que o tombamento em si.

Posteriormente, nos anos 1990, foi instituída a chancela de "paisagem cultural brasileira", através da Portaria 127/1990, definida como: "porção peculiar do território nacional, representativa do processo de interação do homem com o meio natural, ao qual a vida e a ciência humana imprimiram marcas ou atribuíram valores". Tal normativo tem como finalidade contribuir para a preservação do patrimônio cultural e, complementarmente, integrar os instrumentos de proteção e promoção existentes, através do reconhecimento do caráter dinâmico da ação humana sobre o território e de suas transformações, o que busca conferir maior flexibilidade ao instrumento. A concessão da chancela é caracterizada como um pacto de gestão compartilhada, que pode envolver o estabelecimento de plano de gestão entre o poder público, a iniciativa privada e os demais atores civis ou institucionais envolvidos, acompanhados pelo IPHAN. Também é prevista a revisão a cada década, sendo que qualquer pessoa física ou jurídica possui legitimidade para requerer a instauração do processo de chancela.

Já na década posterior, a Portaria 187/2010, também brasileira, dispôs sobre os procedimentos para apuração de infrações administrativas por condutas e atividades lesivas ao patrimônio cultural edificado. Tal fato marcava uma lacuna antiga na salvaguarda do patrimônio nacional, visto que não havia determinação expressa de mitigação de danos de caráter cível ou administrativo. Sendo assim, a imposição de sanções, os meios de defesa e o sistema recursal, e a forma de cobrança dos débitos decorrentes das infrações possivelmente marcam uma nova fase na proteção do patrimônio. A referida portaria determina o regime de multas para infrações na escala de $50 \%$ ou $100 \%$ do dano causado, e $10 \%$ ou $20 \%$ do valor do bem, de acordo com enquadramento no artigo do Decreto-lei 25/1937. Como condicionantes, a portaria vincula a elaboração do plano de fiscalização pelas Superintendências Regionais e, como instrumentos, a notificação para apresentação de documentação / auto de infração / termo de embargo / termo de compromisso (facultativo em substituição à penalidade).

Mais recentemente, a Portaria 420/2010 regulamentou os procedimentos para solicitação, análise e aprovação de intervenções em imóveis, sítios tombados e seus 
entornos. O instrumento conceitua restauração, com foco no imóvel tombado e desarticulação da análise da intervenção de estudos técnicos prévios sobre o conjunto da área tombada. Também determina a explicitação e publicidade dos procedimentos de homogeneização nacional de procedimentos de análise e aprovação em cumprimento à Lei 9784/1999, que regulamenta ritos e procedimentos da administração pública.

Mostra-se válido ressaltar que uma característica marcante em relação aos legislativos dos dois países é que ambos sofrem e sofreram com a carência de regulamentação. De fato, no Brasil, a lei precisou ser regulamentada através de portarias do IPHAN, conforme descrito anteriormente, gerando inclusive uma insegurança jurídica, enquanto que, em Portugal, a lei anterior chegou a ser revogada antes mesmo de ser regulamentada.

No caso dos sítios urbanos, é fácil perceber as dificuldades encontradas em território brasileiro. O tombamento de uma cidade visava a instituir um regime especial, no qual o município tornava-se a entidade guardiã e executora da preservação estabelecida pelo governo federal. No entanto, essa proposta de trabalho mostrou-se fracassada, e instituiu-se a fiscalização por meio de representações locais do próprio IPHAN.

Cabe lembrar que a legislação portuguesa, diferentemente da brasileira, já prevê a classificação por interesse local, trazendo o município para a salvaguarda própria, de modo a integrá-lo no processo de preservação. Por fim, conforme destacou Jorge (2000), uma salvaguarda eficiente do patrimônio necessita de um inventário e de uma classificação sistemática (e que pode ser extrapolada para o tombamento), segundo uma metodologia unitária e que responda às exigências de rigor mais modernas, elementos que viabilizam uma proteção segura ou eficaz.

Extrapolando a legislação em si, temos outros mecanismos de proteção do patrimônio material nos dois países. O IGESPAR, principal instrumento de proteção português legalmente instituído, foi criado somente em 2007, através da fusão do Instituto Português do Património Arquitectónico e do Instituto Português de Arqueologia, incorporando atribuições da direção geral dos edifícios e monumentos nacionais. Já no caso do órgão correspondente brasileiro, o IPHAN, sua criação é anterior à própria lei de salvaguarda, em 1937. 
As respectivas legislações atribuem potenciais equivalentes de salvaguarda aos dois institutos, pelo menos no papel. No entanto, alguns números merecem destaque, referentes ao ano de 2011. No caso português, 331 servidores fizeram parte do quadro funcional neste período, tendo disponíveis quase 24 milhões e 500 mil euros. Já no Brasil, apesar de nosso instituto contar com um efetivo quase três vezes maior (são 976 servidores), possuiu recursos financeiros de apenas 5,5 milhões de reais (CONTROLADORIA GERAL DA UNIÃO, s/d), ou seja, aproximadamente $10 \%$ do valor lusitano, quando convertida a moeda. Estes indicadores são emblemáticos acerca da importância conferida em cada localidade em relação aos principais mecanismos de proteção legalmente instituídos, de forma a representar a relevância atribuída ao campo em cada contexto.

No que tange especificamente à conservação e restauro do patrimônio arquitetônico, cabe salientar as diferenças na persecução penal na busca por sua salvaguarda em ambas as nações. No Brasil, existe o inquérito da Polícia Federal, geralmente desencadeado pelo IPHAN, após dano ao bem tombado, com elaboração de Laudo de Perícia Criminal por perito com formação em engenharia civil. No processo de investigação lusitana, os laudos que visam materializar a prova são produzidos fora da polícia judiciária, através de profissionais com notória especialização no tema.

Dentro dos instrumentos de proteção, também cumpre destacar as diferentes possibilidades de formação em patrimônio, aqui vistos como forma de divulgação, conscientização e salvaguarda, além de indicadores do envolvimento da população com a salvaguarda. Em terras lisboetas, além de diversos cursos técnicos relacionados ao tema, praticamente todas as universidades possuem licenciatura da arte e do patrimônio, e a grande maioria com cursos de pós-graduação relacionados ao tema. No caso brasileiro, a principal formação no campo do conhecimento é através da graduação em arquitetura ou área correlata, com posterior pósgraduação em patrimônio. Torna-se visível, assim, um maior envolvimento da população portuguesa na proteção ao patrimônio histórico, tanto de forma quantitativa quanto qualitativa.

Desta maneira, tendo analisado os aspectos que permeiam os instrumentos de proteção e a arquitetura em âmbito das localidades estudadas, seguem as considerações finais deste artigo. 


\section{Considerações finais}

Para Fischer $(1996,1997)$, as cidades apresentam distintos traços de complexidade, diversidade, pluralidade e contradição. Na visão da autora, elas se caracterizam pela complexa combinação de teias organizacionais, compostas por diversidades, singularidades, exclusões, conflitos, cooperações, ordem, desordem, entre outros aspectos. Nesse âmbito, os casos de Salvador e Lisboa não são diferentes: ambas podem ser chamadas cidades - puzzle, de acordo com o conceito de Fischer (1997), compostas de fragmentos distintos, formando um todo coerente, reconfigurado - e, simultaneamente, uma organização complexa, que, como outras metrópoles, enfrentam vários desafios contemporaneamente.

Nossa análise objetivou contemplar questões envolvidas na salvaguarda do patrimônio arquitetônico nas cidades de Salvador e Lisboa, sob duas dimensões: em âmbito arquitetônico e também em termos de seus instrumentos de proteção. Do ponto de vista da arquitetura de seu patrimônio material, podemos dizer que as duas cidades apresentam similaridades significativas, marcadores de uma história em comum e das influências mútuas ao longo dos séculos. Tal fato é evidenciado através de características arquitetônicas em comum, como revestimentos em fachadas, partidos em "U", pátio ou átrio central e outros elementos construtivos, adotados em edificações nas duas localidades. Conforme exposto anteriormente, também merece destaque a unificação das técnicas nos diferentes ramos da construção relacionados à recuperação de bens móveis e imóveis, através das regras da Congregação de São Bento para a circulação dos monges entre as unidades lisboetas e soteropolitanas.

Com relação aos aparelhos legais de salvaguarda, vimos que a legislação, por si só, não representa um instrumento capaz de proteger os patrimônios materiais de uma localidade. Da mesma maneira, a lei não configura a única possibilidade no que tange a tal salvaguarda. Se assim fosse, Lisboa não teria tantos patrimônios arquitetônicos conservados, tendo em vista que a primeira legislação robusta produzida pelos lusos nesse domínio data da década de 1980. Em âmbito brasileiro, e especialmente em se tratando da capital baiana, dispomos de uma regulamentação mais antiga e com mecanismos equivalentes aos portugueses de proteção; ainda assim, a salvaguarda de nosso patrimônio não se mostra tão 
consistente e possui dimensões claramente reduzidas, se a compararmos com a de nossos irmãos europeus.

Não obstante, a recenticidade de uma legislação portuguesa mais robusta, em comparação com a brasileira, paradoxalmente, Lisboa possui uma impressionante riqueza cultural e histórica da cidade em relação à arquitetura, principalmente no que tange à preservação destes imóveis.

Entender a lei como expressão da vontade geral pode fornecer-nos uma valiosa pista para esta aparente contradição. Uma das possíveis respostas está associada à pouca necessidade anterior de salvaguarda em âmbito lusitano, sendo possível utilizar essa suposição como ponto de partida para estudos sobre o tema, tendo como suporte uma análise cultural. Jorge (2000) apresenta uma interessante contribuição a respeito dessa hipótese, ao defender a consciência comunitária portuguesa na salvaguarda do patrimônio cultural:

\footnotetext{
É um facto social incontestado que, cada vez mais, os cidadãos têm consciência comunitária do valor histórico e da riqueza etnográfica do seu património coletivo, espelho e vector da sua identidade cultural, mobilizando-se com vontade empatizada e determinação assumidas na tarefa urgente e incessante da sua defesa (JORGE, 2000, p. 7).
}

Nesse sentido, consideramos a própria dimensão cultural como uma questão que pode ser a chave para a compreensão da salvaguarda do patrimônio das cidades estudadas. Boito (2005) já antecipava, em 1884, o que parece ser a chave principal para a efetiva salvaguarda brasileira, através de um olhar coletivo de proteção e de um sentimento que deve ultrapassar a identidade nacional, para alinhar-se à preservação da história de um povo:

\footnotetext{
Para bem restaurar é necessário amar e entender o monumento, seja estátua, quadro ou edifício, sobre o qual se trabalha, e do mesmo modo para a arte antiga em geral. Ora, que séculos souberam amar e entender as belezas do passado? E nós, hoje, em que medida sabemos amá-las e entendê-las? (BOITO, 2005, p. 31)
}

Uma possibilidade de investigação frutífera, pois, parece-nos essa dimensão, no que tange à própria importância dos poderes locais. O que podemos dizer com relação ao controle social exercido por lisboetas e soteropolitanos em seus respectivos contextos? Talvez tenhamos a aprender com os lisboetas, na busca pela identificação, valorização e salvaguarda do patrimônio cultural arquitetônico, 
apropriando-o como de nossa efetiva propriedade e responsabilidade. As formas de encarar o patrimônio material, bem como de ver o espaço público e privado, dimensões que se constroem ao longo da história, podem ser pistas interessantes para futuras pesquisas.

Finalmente, podemos dizer que as análises e reflexões aqui colocadas podem contribuir para pensar a "consciência patrimonial" nas conjunturas estudadas. Considerando, conforme apresentado anteriormente, a abertura de um campo de discussões sobre o patrimônio, necessariamente interdisciplinar, domínio em que caracterizamos uma realidade na qual o espaço não só se configura como físico, mas também social e simbólico; por isso, a dimensão humana deve ser pensada para que se compreendam os significados que levam determinado espaço a se tornar um patrimônio, e, principalmente, a se manter e ser reconhecido, respeitado e conservado como tal. Dessa forma, as interpretações, ressignificações do espaço e reconstruções das memórias, e, consequentemente, as possibilidades de salvaguarda do patrimônio material, passam não só, pelo conhecimento das leis, mas também da história e do contexto cultural desse patrimônio e da própria cidade. Pois, afinal, aquele que não conhece a história de sua cidade, dela "não é cidadão [...], é hóspede" (MACEDO, 1993). 


\section{Referências}

ANICO, M. A pós-modernização da cultura: património e museus na contemporaneidade. Horizontes Antropológicos, Porto Alegre, ano 11, n. 23, p. 71-86, jan./jun. 2005.

ARANTES, R. A.; CARVALHO, I. Os condomínios residenciais fechados na Região Metropolitana de Salvador. Bahia análise \& dados, Salvador, v. 19, n. 3, p. 735-746, out./dez. 2009.

BAPTISTA, L. V. Dominação demográfica no contexto do século XX português: Lisboa, a capital. Sociologia - problemas e práticas, Lisboa, n. 15, p. 53-77. 1994.

BARATA SALGUEIRO, T. Lisboa, metrópole policêntrica e fragmentada. Finisterra, v. XXXII, n. 63, p. 179-190. 1997.

BOITO, C. Os Restauradores. Ateliê Editorial. São Paulo, 2005.

CARVALHO, I. M. M.; PEREIRA, G. C. Dinâmica metropolitana e segregação socioespacial. Caderno CRH, Salvador, v. 20, n. 50, p. 261-279, maio/ago. 2007.

CONTROLADORIA GERAL DA UNIÃO. Disponível em:

$<$ http://www.portaldatransparencia.gov.br>. Acesso em: 08 set. 2012.

DOREA, L. E. Histórias de Salvador nos nomes das suas ruas. Salvador: Edufba, 2006.

FERREIRA, M. L. M. Patrimônio: as várias dimensões de um conceito. História em Revista, Pelotas, v.10, p. 29-39, dez. 2004.

FERREIRA, V. M. Urbanidade e Cosmopolitismo de Lisboa. Cidades - Comunidades e Territórios, n. 5, p. 127-138, dez. 2002.

FISCHER, T. M. D. Gestão contemporânea: cidades estratégicas - aprendendo com fragmentos e reconfigurações do local. In: FISCHER, T. M. D. Gestão contemporânea: cidades estratégicas e organizações locais. Rio de Janeiro: Fundação Getúlio Vargas, 1996. p. 13-26. 
FISCHER, T. M. D. A cidade como teia organizacional: inovações, continuidades e ressonâncias culturais - Salvador da Bahia, cidade puzzle. Revista de Administração Pública, Rio de Janeiro, v. 31, n. 3, p. 74-88, maio/jun. 1997.

FONSECA, J. D. 1755 O Terramoto de Lisboa. Lisboa: Argumentum, 2005.

GIL, A. C. Como elaborar projetos de pesquisa. São Paulo: Atlas, 2002.

GRAMMONT, A. M. A construção do conceito de Patrimônio Histórico: restauração e cartas patrimoniais. PASOS - Revista de Turismo y Patrimonio Cultural, La Laguna, v. 4, n. 3, p. 437-442, set. 2006.

HERNANDEZ, M. H. O. Territórios e Patrimônio: acerca da relaçãoentre os mosteiros beneditinos do Brasil e Portugal na conservação dos benstemporais e espirituais. In: ENCONTRO ANUAL DA ASSOCIAÇÃO NACIONAL DE PESQUISADORES EM ARTES PLÁSTICAS, v. 19, 2010. Anais... Cachoeira: ANPAP, 2010.

INSTITUTO BRASILEIRO DE GEOGRAFIA E ESTATÍSTICA (IBGE). Censo 2010. Disponível em:

$<$ http://www.ibge.gov.br/home/estatistica/populacao/censo2010/tabelas pdf/Brasil tab 1 6.pdf>. Acesso em: 27 jul. 2012.

INSTITUTO DE GESTÃO DO PATRIMÔNIO ARQUITETÓNICO E ARQUEOLÓGICO (IGESPAR). 2012. Disponível em: <http://www.igespar.pt/pt/>. Acesso em: 17 ago. 2012.

INSTITUTO NACIONAL DE ESTATÍSTICA. Censos 2011: resultados provisórios. Disponível em $<$ http://censos.ine.pt/xportal/xmain?xpid=CENSOS\&xpgid=ine censos publicacao det \&menuBOUI=13707294\&contexto=pu\&PUBLICACOESpub boui=122073978\&PUBLIC ACOESmodo=2\&selTab=tab1>. Acesso em: 17 ago. 2012.

INSTITUTO DO PATRIÔNIO ARTÍSTICO E CULTURAL DA BAHIA (PAC-BA). Disponível em: <http://www.ipac.ba.gov.br/>. Acesso em: 17 ago. 2012.

JORGE, V. F. Património e Identidade Nacional. Revista Engenharia Civil, Évora, n. 9, p. 5-12. 2000.

LEI 107/2001. Diário da República, I série-A, n. 209, set., p. 5808-5829. 2001. Disponível em: <http://dre.pt/pdf1s/2001/09/209A00/58085829.pdf>. Acesso em: 17 ago. 2012.

Cad. de Pesq. Interdisc. em Ci-s. Hum-s. Florianópolis, Santa Catarina, Brasil, ISSN 1984-8951 v.14, n.105, p.139-164 ago/dez 2013 
MACEDO, F. R. História de Porto Alegre. Porto Alegre: Editora da Universidade, 1993.

MARIANO, A. A invenção da baianidade. São Paulo: Annablume, 2009.

NORA, P. Les lieux de mémoire. Paris: Quarto Gallimard, 1997.

PESAVENTO, S. J. Cidades visíveis, cidades sensíveis, cidades imaginárias. Revista Brasileira de História, São Paulo, v. 27, n. 53, jun. 2007.

PINHEIRO, M. L. B. Origens da Noção de Preservação do Patrimônio Cultural no Brasil. Revista de pesquisa em arquitetura e urbanismo, São Paulo, n. 3, fev. 2006.

RISÉRIO, A. Uma história da Cidade da Bahia. Rio de Janeiro: Versal, 2004.

RODRIGUES, T. Um espaço urbano em expansão: de Lisboa de Quinhentos à Lisboa do século XX. Penélope: fazer e desfazer a História, Lisboa, n. 13, p. 94-117. 1994.

RUBIM, A. A. C.; COUTINHO, S.; ANCINTARA, P. H. Salvador nos anos 50 e 60: encontros e desencontros com a cultura. Revista de Urbanismo e Arquitetura, Salvador, v. 3, n. 1. 1990.

SANTOS, J. A cidade poli(multi)nucleada: a reestruturação do espaço urbano em Salvador. 2008. 402 f. Tese (Doutorado em Geografia) - Faculdade de Ciência e Tecnologia, Universidade Estadual Paulista, Presidente Prudente, 2008.

SANTOS, S. Imagens da cidade planeada: A diversidade cultural e o pensamento estratégico urbano de Lisboa. Sociologia, problemas e práticas, Lisboa, n. 57, p. 131$151,2008$.

SCOTT, A. S. Os portugueses. São Paulo: Contexto, 2010.

SERPA, A. O espaço público na cidade contemporânea. São Paulo: Contexto, 2007.

SILVA, A. F.; MATOS, A. C. Urbanismo e modernização das cidades: o "embellazamento" como ideal, Lisboa, 1858-1891. Scripta Nova: Revista Electrónica de 
Geografía y Ciencias Sociales Universidad de Barcelona, Barcelona, v. 30, n. 69, ago. 2000.

SISTEMA DE INFORMAÇÃO PARA O PATRIMÓNIO ARQUITECTÓNICO (SIPA). 2012. Disponível em: <http://www.monumentos.pt>. Acesso em: 15 set. 2012.

STRAUSS, A.; CORBIN, J. Pesquisa qualitativa. Porto Alegre: Artmed, 2008.

URIARTE, U. M. O lugar da História no consumo do chamado Patrimônio Histórico. In: ENCONTRO ANUAL DE ESTUDOS MULTIDISCIPLINARES EM CULTURA, v. 6, 2010, Salvador. Anais... Salvador: CULT, 2010.

WEINSTEIN, M. Lisboa e Salvador, quão semelhantes. Jornal A Tarde. Salvador, Caderno Cidades, 25 nov. 2007.

ZAMIN, F. Patrimônio cultural do Rio Grande do Sul - a atribuição de valores a uma memória coletiva edificada para o Estado. 2006. 150 f. Dissertação (Mestrado em História) - Instituto de Filosofia e Ciências Humanas, Universidade Federal do Rio Grande do Sul, Porto Alegre, 2006.

Artigo:

Recebido em: 18/02/2013

Aceito em: 09/10/2013 